\title{
T. Mudrovčić*
}

\section{SIGURAN RAD U HLADNJAČAMA}

UDK 637.513.8:331.45

PRIMLJENO: 2.2 .2017$.

PRIHVAĆENO: 31.5 .2015$.

\begin{abstract}
SAŽETAK: Premda u hrvatskom zakonodavstvu postoji velik broj propisa iz područja zaštite na radu, još su neka područja rada slabo obuhvaćena i regulirana. Takva je situacija i s radom radnika u hladnjačama.

Duljina boravka radnika u hladnjači, broj ulazaka i izlazaka tijekom jedne smjene, obvezno osiguranje određenog vremena zadržavanja u pretprostoru, osiguranje odgovarajuće osobne zaštitne opreme samo su neke od mjera koje poslodavac treba poduzeti kako bi spriječio negativan učinak rada u hladnjačama za radnikovo zdravlje.

Cilj ovog rada je dati preporuke o tome kako organizirati rad u hladnjačama s ciljem smanjenja rizika štetnog utjecaja niskih temperatura na zdravlje radnika na najmanju moguću mjeru.
\end{abstract}

Ključne riječi: hrvatsko zakonodavstvo, duljina boravka radnika u hladnjačama, osobna zaštitna oprema

\section{UVOD}

Hladnjače su prostorije čija je namjena čuvanje svježih ili smrznutih proizvoda njihovim rashlađivanjem. Osnovni načini rashlađivanja su hlađenje i zamrzavanje.

Hlađenje se primjenjuje u svrhu očuvanja poljoprivrednih proizvoda te polugotovih i gotovih prehrambenih proizvoda pri temperaturama zraka u rasponu od $1^{\circ} \mathrm{C}$ do $12^{\circ} \mathrm{C}$.

Zamrzavanje je postupak koji se primjenjuje za istu namjenu, ali za dulje čuvanje proizvoda, pa su i temperature zraka u njima niže (od $-1^{\circ} \mathrm{C}$ do $-70^{\circ} \mathrm{C}$ ), ovisno o vrsti poljoprivrednih ili prehrambenih proizvoda te planiranom vremenu skladištenja. Osim hladnjača za zamrzavanje

*Tina Mudrovčić, dipl. ing. sigurnosti, (tmudrovcic@hzzzsr.hr), Hrvatski zavod za zaštitu zdravlja i sigurnost na radu, Cimermanova 64a, 10020 Zagreb. postoje i posebne komore koje nazivamo tunelima za zamrzavanje, a služe za brzo zamrzavanje proizvoda prije skladištenja u hladnjači za zamrzavanje (Rashlađivanje namirnica, 2017.).

\section{UTJECAJ HLADNOĆE NA RADNIKA}

Radnici koji rade u hladnjačama primorani su često ulaziti i izlaziti iz hladnjače, ali i neko vrijeme boraviti u njoj, pri čemu su izloženi velikim temperaturnim razlikama što predstavlja rizik za njihovo zdravlje. Nagla promjena temperature uzrokovana čestim ulascima/izlascima $\mathrm{u}$ /iz područja niskih temperatura (nižih od $0^{\circ} \mathrm{C}$ ) u područje sobne ili više temperature nepovoljno utječe na zdravlje radnika jer od organizma zahtijeva iznimnu prilagodbu, prvenstveno srčano-žilnog sustava.

Propisi i preporuke mjerodavnih institucija iz područja zaštite na radu ne definiraju koliko 
trebaju trajati odmori, vrijeme koje radnik treba provesti u pretprostoru prije ulaska/izlaska u/iz hladnjače te temperaturu pretprostora hladnjače tijekom radnikovog rada u hladnjači.

Najblaži simptom hlađenja tijela uzrokuje osjećaj neugode, što može biti ometajući čimbenik prilikom izvođenja radnih zadataka. Nadalje, hladnoća uzrokuje smanjenje fizičkih (npr. smanjenje spretnosti prstiju) i mentalnih sposobnosti.

Udisanje hladnog zraka može dovesti do razvoja mnogih respiratornih bolesti, čiji se simptomi pogoršavaju s godinama, prilikom težeg fizičkog rada te u slučaju prethodnih težih respiratornih bolesti. Rad pri niskim temperaturama povećava pobol i smrtnost od bolesti srčano-žilnog sustava (Mäkinen, Hassi, 2009.).

Ako radnik mora prilikom rada dodirivati metalne površine, to mora činiti u rukavicama jer na temperaturama nižim od $0{ }^{\circ} \mathrm{C}$ može doći do pojave ozeblina.

\section{MJERE ZAŠTITE}

Radnici se prije rasporeda na poslove pri niskim temperaturama moraju uputiti na prethodni zdravstveni pregled te periodično svaka 24 mjeseca, kako bi se utvrdilo da su zdravstveno sposobni za rad u hladnjači. Prethodni i periodični zdravstveni pregledi propisani su Pravilnikom o poslovima s posebnim uvjetima rada.

Kada radnici moraju dulje vrijeme provesti u hladnjači, posao treba organizirati na način da se osigura dovoljan broj radnika kako bi se posao obavio u predviđenom vremenu, a zadržavanje radnika u hladnjači svelo na najmanje moguće.

Svim tim radnicima treba osigurati odgovarajuću osobnu zaštitnu odjeću i obuću koja podrazumijeva: zaštitne cipele, zaštitnu kapu, jaknu, hlače i rukavice za niske temperature. Daljnje mjere zaštite na radu odnose se na osiguranje toplih napitaka i redovitih odmora tijekom svakog sata rada.

Poznato je da se u slučaju nepostojanja propisanih pravila zaštite na radu mogu koristiti u praksi provjereni načini pomoću kojih se opasnosti na radu otklanjaju ili smanjuju, odnosno priznata pravila zaštite na radu. Kao pomoć u rješavanju pitanja odmora radnika u hladnjači mogu poslužiti preporuke FAO (Food and Agriculture Organisation) organizacije Ujedinjenih naroda u kojima se savjetuje kao uobičajeni raspored za rad u hladnjači (temperatura $-20^{\circ} \mathrm{C}$ i niže) da se nakon svakih 50 minuta rada, 10 minuta radnik zagrijava u prostoriji temperature od $20^{\circ} \mathrm{C}$ do $27^{\circ} \mathrm{C}$ (Freezing and refrigerated..., 2017.).

Budući da se radi u temperaturnom okolišu koji se smatra vrlo teškim za rad, treba uvijek raditi u paru ili skupini, a sama rashladna prostorija treba imati mogućnost otvaranja vrata rukom s unutarnje strane. Prilikom fizičke aktivnosti treba disati kroz nos i ni pod kojim uvjetima ne raditi pod utjecajem opojnih sredstava ili alkohola. Alkoholna pića stvaraju lažni učinak "grijanja" tijela jer uzrokuje periferno proširenje krvnih žila, što dovodi veću količinu krvi na periferiju zbog čega dolazi do brzog pothlađivanja krvi, a time i čitavog organizma.

Novim radnicima, koji još nisu radili u ovakvim uvjetima, treba omogućiti postupnu aklimatizaciju koju treba provoditi tijekom prvog tjedna rada. Aklimatizacija podrazumijeva postupno privikavanje organizma na novi okoliš uz postupno opterećenje organizma tijekom prvog tjedna rada uz korištenje češćih kratkih pauza.

Budući da je pod u hladnjači zbog velike temperaturne razlike između okolnog područja i hladnjače sklon stvaranju leda, poslodavac treba dati uputu na koji način sigurno čistiti pod. Sami radnici moraju oprezno hodati takvim zaleđenim površinama kako ne bi došlo do poskliznuća i pada. Svi putovi za kretanje moraju biti čisti i prohodni.

U hladnu prostoriju ne treba ulaziti oznojen, a tijekom rada u hladnim prostorijama radove izvoditi umjerenim tempom kako bi se spriječilo prekomjerno zagrijavanje i znojenje organizma. Ako odjeća postane vlažna, treba ju mijenjati jer vlažna odjeća smanjuje izolaciju odijela zbog zadržavanja vlage u procesu kako se odjeća suši (Uputa za rad u hladnim prostorijama, 2017.).

Kod fizičkog rada u komori jedina barijera između tijela i hladnog okoliša je odjeća koju rad- 
nik nosi na sebi, pa je poglavlje osobne zaštitne opreme posebno obrađeno u nastavku.

\section{OSOBNA ZAŠTITNA OPREMA}

Ako radni proces $u$ hladnjačama nije mehaniziran ili automatiziran, odnosno radni proces obavljaju radnici u hladnjači, tada im se mora dodijeliti osobna zaštitna oprema koja će ih štititi od niskih temperatura.

Osobna zaštitna oprema mora biti izrađena od materijala koji su otporni na niske temperature i imaju dobra izolacijska svojstva. Bilo kakav rad u prostorima hladnjače bez odgovarajuće osobne zaštitne opreme ugrožavao bi život i zdravlje radnika. Zbog toga poslodavac mora osigurati da radnici ne ulaze, zadržavaju se ili rade u prostorijama hladnjače bez odgovarajuće osobne zaštitne opreme koja mora biti neoštećena i ispunjavati funkciju zaštite. Radnici se moraju držati danih radnih uputa o korištenju i održavanju osobne zaštitne opreme.

Najvažnije karakteristike osobne zaštitne opreme koja se koristi pri radu u hladnjačama:

- Obuća mora imati dobru izolaciju od hladnoće i odabire se prema normi HRN EN ISO 20344:2007/A1:2008 - Osobna zaštitna oprema - Sigurnosna obuća. Gornji dio obuće mora biti izrađen od kože, podstava od materijala koji pruža dobru toplinsku izolaciju, a potplat mora biti vodonepropustan i otporan na klizanje (slika 1).

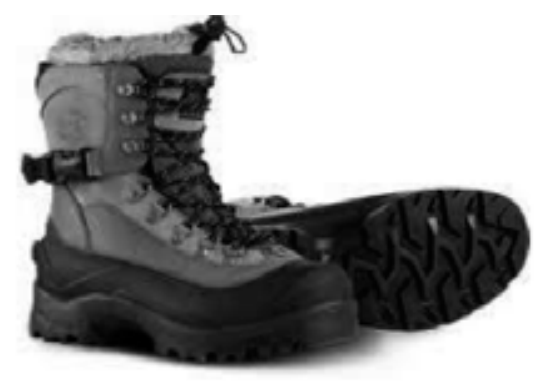

Slika 1. Zaštitna obuća za zaštitu od hladnoće

Figure 1. Personal protective boots for working in cold storage facilities

- Potrebno je nositi 2 para čarapa (radi bolje zaštite), ali ne pamučnih, zbog loših izolacijskih svojstava i upijanja vlage zbog čega stopalo može biti neprestano vlažno. Idealan sastav materijala za čarape je $60-70 \%$ vuna u kombinaciji sa $30-40 \%$ umjetnih vlakana.

- Odjeća može biti u obliku jednodijelnog kombinezona koji pokriva cijelo tijelo ili jakna u kompletu $\mathrm{s}$ hlačama kao dvodijelno odijelo (slika 2). Zahtjevi i metode ispitivanja odjevnih predmeta za zaštitu tijela u hladnim okruženjima navedeni su u normi HRN EN 342:2004 - Zaštitna odjeća: kompleti i odjevni predmeti za zaštitu od hladnoće.

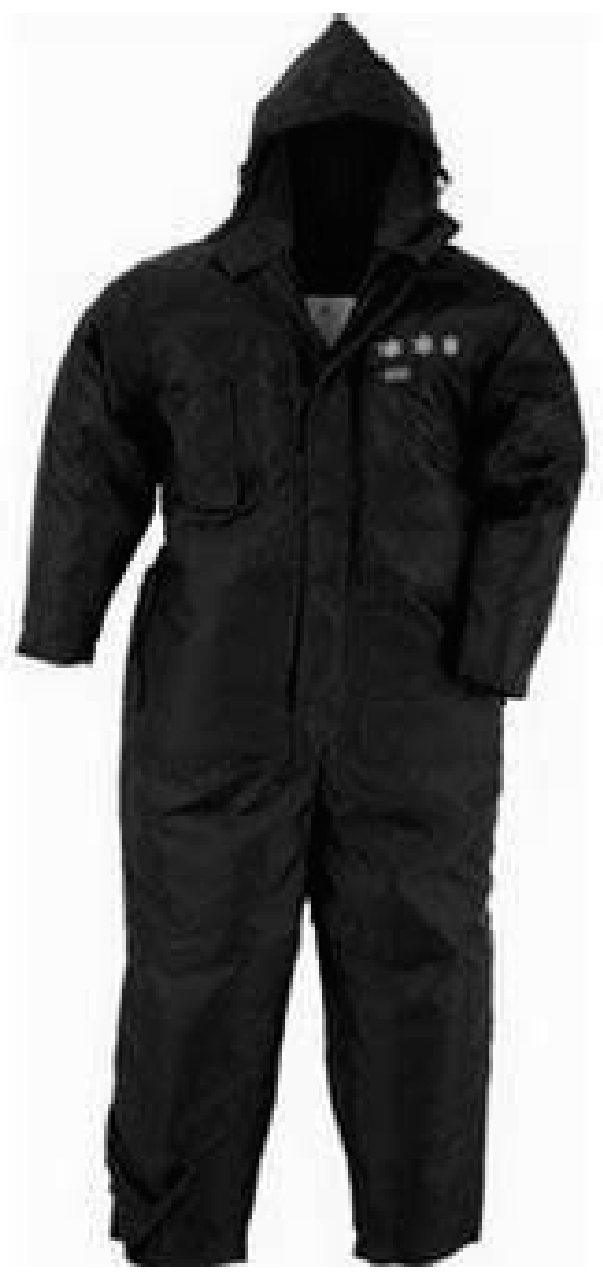

Slika 2. Zaštitna odjeća za zaštitu od hladnoće

Figure 2. Personal protective clothes for working in cold storage facilities

Prilikom rada na niskim temperaturama preporučuje se nošenje više slojeva odjeće zbog bolje zaštite. Slojevita odjeća omogućava radniku ski- 
danje pojedinog sloja ako dođe do prekomjernog zagrijavanja i znojenja. Razlikuju se 3 sloja odjeće:

- bazični ili intimni sloj odjeće

- središnji sloj odjeće (puloveri, majice)

- vanjski sloj odjeće (jakne).

Od pokrivala za glavu, potrebno je koristiti kape ili potkape. Potkape su korisni dodaci koji se nose ispod kacige (ako je potrebno nositi kacigu), a dobre su i zbog zaštite sinusa, ušiju, vrata te upijanja znoja (slika 3).

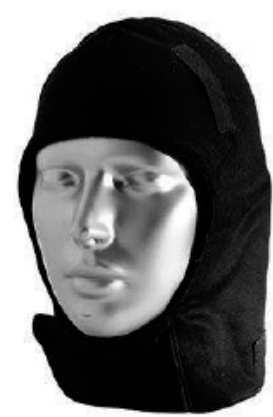

Slika 3. Potkapa za zaštitu od hladnoće

Figure 3. Head cover for working in cold storage facilities

Za zaštitu ruku od hladnoće potrebno je nositi zaštitne rukavice (slika 4) koje udovoljavaju zahtjevima i metodama ispitivanja rukavica prema normi HRN EN 511:2007 - Rukavice za zaštitu od hladnoće - zahtjevi i metode ispitivanja rukavica za zaštitu od hladnoće do $-50^{\circ} \mathrm{C}$ (Cold environment, 2017.).

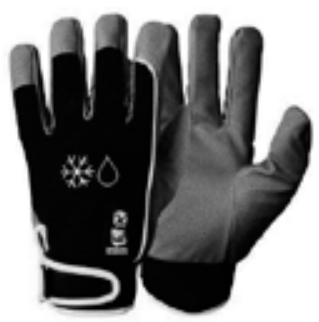

Slika 4. Zaštitne rukavice za zaštitu od hladnoće

Figure 4. Personal protective gloves for working in cold storage facilities

\section{PRVA POMOĆ}

Kod pružanja prve pomoći osobama koje su bile izložene utjecaju niskih temperatura treba se držati sljedećih pravila (Prva pomoć - smrzotine, 2017.):

- Osobu treba uvesti u toplu prostoriju i skinuti joj odjeću, obuću i prstenje. Komadi tkanine koji su zalijepljeni za kožu ne smiju se nasilno skidati, već ih treba obrezati škarama.

- Smrzotine pokrijte gazom, ali ne omatajte zavojem.

- Ruku ili nogu sa smrzotinom treba imobilizirati i staviti u povišen položaj.

- Ne trljajte promrzle dijelove tijela.

- Ne bušite mjehure.

- Ne stavljajte prašak, mast i sl. na smrzotinu.

- Ne navlačite rukavice ili čarape na smrznute okrajine.

- Ne zagrijavajte promrzle okrajine termoforom i sličnim izvorima topline.

- Ne dopustite osobi sa smrznutim stopalom da hoda.

- U slučaju da je osoba bez svijesti, staviti je u bočni položaj, provjeriti diše li i zvati hitnu pomoć.

- Ako osoba ne diše, potrebno je započeti s oživljavanjem.

\section{ZAKLJUČAK}

Ono što poslodavac mora, u skladu s odredbama Zakona o zaštiti na radu, je osigurati uvjete rada na radnom mjestu koji neće štetno utjecati na život i zdravlje radnika. Prije svega sva radna mjesta na kojima radnici obavljaju poslove u hladnjači moraju biti navedena u procjeni rizika.

Budući da rad u ekstremno hladnom okolišu nije dovoljno "pokriven“ našim propisima, potrebno je koristiti se saznanjima i u praksi provjerenim postupcima kojima se može sačuvati zdravlje radnika. Posebno se to odnosi na organizaciju rada i određivanje koliko pauza treba osigurati radniku, poznavanje normi povezanih s odjećom za rad pri niskim temperaturama kao i omogućavanje novim radnicima aklimatizaciju na nove radne uvjete. 
Naravno, nakon provedenih svih mjera zaštite treba ocijeniti razinu rizika kojem su radnici izloženi, a tijekom rada treba pratiti primjenu preventivnih mjera i po potrebi primjenjivati nove kako bi se sačuvalo zdravlje i sigurnost radnika u hladnjači.

\section{LITERATURA}

Cold Enviroments. Working in the Cold, dostupno na: http://www.ccohs.ca/oshanswers/ phys_agents/cold_working.html, pristupljeno 10.1.2010.

Freezing and refrigerated storage in fisheries, dostupno na: http://www.fao.org/docrep/003/ v3630e/v3630e12.htm, pristupljeno 30.1.2017.
Mäkinen, T.M., Hassi, J.: Health problems in cold work. Ind Health. 47, 2009., 3, 207-220.

Prva pomoć - smrzotine, dostupno na: http:// www.hitnazg.hr/prva-pomoc/smrzotine, pristupljeno 26.1.2017.

Pravilnik o poslovima s posebnim uvjetima rada, N.N., br. 5/84.

Rashlađivanje namirnica, dostupno na: http:// polj.uns.ac.rs/Files/tehnologijapp/11\%20-\%20 Rashlađivanje\%20namirnica.pdf, pristupljeno 30.1. 2017.

Uputa za rad u hladnim prostorijama, dostupno na: http://www.znrinfo.com/index.php/upute-i-metodologije/upute-za-rad/81-uputa-za-radu-hladnim-prostorijama, pristupljeno 26.1.2017.

\section{WORK SAFETY IN COLD STORAGE FACILITIES}

SUMMARY: Although Croatian legislation has passed a large number of policies regarding work safety, some areas of work are still neglected and loosely regulated. This is the case with working in cold storage facilities.

The duration of working inside the cold storage chamber, the number of exits and entries during one shift, the mandatory resting period in a heated ante-chamber and the provision of necessary personal protective equipment are just some of the measures the employer needs to take in order to prevent adverse health effects in workers.

The objective of this study is to recommend a work process in cold storage facilities that would reduce the risk of adverse health consequences from working at low temperatures to a minimum.

Key words: Croatian legislation, duration of work in cold storage chambers, personal protective equipment 